\title{
Depression and Anxiety Changes Among Sexual and Gender Minority People Coinciding with Onset of COVID-19 Pandemic
}

J Gen Intern Med 35(9):2788-90

DOI: $10.1007 / \mathrm{s} 11606-020-05970-4$

(C) The Author(s) 2020

\section{INTRODUCTION}

With SARS-COV-2 recently sweeping the globe, the population is experiencing a group stressor unlike any phenomenon in this country in the last century. How the pandemic experience is related to mental health challenges including anxiety and depression is unknown. Numerous factors - such as changes in community function; restriction of activities and social contacts; and fearfulness about the virus, the economic downturn, and food access-may contribute to poorer mental health. Marginalized populations, such as sexual and gender minority people (i.e., non-heterosexual people and transgender or gender-expansive people, respectively) may be particularly at risk for adverse impacts of the pandemic due to preexisting economic and health factors. ${ }^{1}$ We set out to document changes in depression and anxiety within The PRIDE Study, a longitudinal cohort of sexual and gender minority people, a vulnerable population. ${ }^{2}$

\section{METHODS}

Participants in The PRIDE Study, a longitudinal cohort study of sexual and gender minority people, ${ }^{2}$ were included if they completed mental health measures in the 2019 Annual Questionnaire (timepoint 1, June 2019 - ongoing at time of data extraction) and in a COVID-19 impact ancillary study (timepoint 2, March 23, 2020, through April 19, 2020). Paired sample $t$ tests examined changes in depression (9-item Patient Health Questionnaire, PHQ- $9^{3}$ ) and anxiety (7-item Generalized Anxiety Disorder Scale, GAD- $7^{4}$ ) symptoms overall and separately among those who screened positive (PHQ-9 and GAD-7 scores $\geq 10^{3,4}$ ) and negative ( scores $<10$ ) for depression and generalized anxiety disorder at timepoint 1 .

Received May 5, 2020

Revised May 5, 2020

Accepted June 5, 2020

Published online June 17, 2020

\section{RESULTS}

In total, 2288 participants were included in this study (see Table 1 for participant characteristics). Depression symptoms increased by a mean PHQ-9 score of $1.21(t[2280]=11.35, p<.001, d=.20)$ from timepoint 1 to 2 . Anxiety symptoms increased by a mean GAD-7 score of $3.11(t[2282]=27.95, p<.001, d=.54)$. Among individuals who screened positive for depression at timepoint 1 , PHQ-9 scores decreased by a mean of $1.08(t[670]=-4.80$, $p<.001, d=.21)$ at timepoint 2. Among individuals who screened negative for depression at time 1, PHQ-9 scores increased by a mean of $2.17(t[1609]=19.58, p<.001, d=0.53)$ at timepoint 2. Among individuals who screened positive for generalized anxiety at timepoint 1 , there was no change in GAD-7 scores $(t[508]=1.01, p=.32, d=.06)$. Among individuals who screened negative for generalized anxiety at timepoint 1 , GAD-7 scores increased by a mean of $3.93(t[1773]=32.93$, $p<.001, d=.88)$ at timepoint 2 .

\section{DISCUSSION}

We found increases in anxiety and depression coinciding with the COVID-19 pandemic onset. Increased anxiety and depression symptoms were driven by people who did not have preexisting symptoms consistent with generalized anxiety or depression. While this study was conducted with sexual and gender minority people, the results may be relevant for other vulnerable populations, such as other minority groups.

Health care providers are advised to check in with patients about stress and to screen for mood and anxiety disorders, even among patients who had no prior history of anxiety or depression. Treatment and referrals can include traditional interventions such as individual therapy and medications and may also include COVID-19-specific supports implemented on a larger scale (e.g., supportive peer-led groups, mindfulness practice). This study is observational. Our finding that individuals with preexisting depression had improved mood from timepoint 1 to 2 may represent regression to the mean and should not be interpreted that these individuals have less depressive symptoms, as they already were experiencing symptoms of depression at timepoint 1. Future research will identify who is most at risk for adverse impact. In the interim, we should consider ways to support the mental health of all of our communities during the pandemic, with special care and attention to vulnerable populations. 
Table 1 Demographic characteristics of $N=\mathbf{2 2 8 8}$ sexual and gender minority individuals

\begin{tabular}{|c|c|}
\hline \multicolumn{2}{|l|}{ Participant characteristics } \\
\hline Age: mean, median (SD) & $36.9,31.9(14.7)$ \\
\hline \multicolumn{2}{|l|}{ Race/ethnicity, ${ }^{\mathrm{a}}$ (\%) } \\
\hline American Indian/Alaska Native & $65(2.8 \%)$ \\
\hline Asian & $98(4.3 \%)$ \\
\hline Black/African American & $78(3.4 \%)$ \\
\hline Hispanic, Latino, or Spanish & $128(5.6 \%)$ \\
\hline Middle Eastern or North African & $28(1.2 \%)$ \\
\hline Native Hawaiian or Pacific Islander & $7(0.3 \%)$ \\
\hline White & $2116(92.5 \%)$ \\
\hline Another race or ethnicity & $26(1.1 \%)$ \\
\hline \multicolumn{2}{|l|}{ Sexual orientation, ${ }^{\mathrm{a}} n(\%)$} \\
\hline Asexual & $268(11.7 \%)$ \\
\hline Bisexual & $693(30.3 \%)$ \\
\hline Gay & $834(36.5 \%)$ \\
\hline Lesbian & $467(20.4 \%)$ \\
\hline Pansexual & $320(14.0 \%)$ \\
\hline Queer & $923(40.3 \%)$ \\
\hline Questioning & $56(2.4 \%)$ \\
\hline Same-gender loving & $97(4.2 \%)$ \\
\hline Straight/heterosexual & $39(1.7 \%)$ \\
\hline Two-spirit & $13(0.6 \%)$ \\
\hline Another sexual orientation & $86(3.8 \%)$ \\
\hline \multicolumn{2}{|l|}{ Gender, ${ }^{\mathrm{a}, \mathrm{b}} n(\%)$} \\
\hline Agender & $99(4.3 \%)$ \\
\hline Cisgender $\operatorname{man}^{\mathrm{c}}$ & $418(18.3 \%)$ \\
\hline Cisgender woman ${ }^{\mathrm{c}}$ & $623(27.2 \%)$ \\
\hline Genderqueer & $300(13.1 \%)$ \\
\hline Man & $562(24.6 \%)$ \\
\hline Non-binary & $438(19.1 \%)$ \\
\hline Questioning & $85(3.7 \%)$ \\
\hline Transgender man & $279(12.2 \%)$ \\
\hline Transgender woman & $124(5.4 \%)$ \\
\hline Two-spirit & $23(1.0 \%)$ \\
\hline Woman & $500(21.9 \%)$ \\
\hline Another gender identity & $134(5.9 \%)$ \\
\hline \multicolumn{2}{|l|}{ Sex assigned to individual at birth, $n(\%)$} \\
\hline Female & $1428(63.0 \%)$ \\
\hline Male & $840(37.0 \%)$ \\
\hline \multicolumn{2}{|l|}{ Highest level of education, $n(\%)$} \\
\hline Less than high school completion & $20(0.9 \%)$ \\
\hline High school diploma or equiv. & $487(21.3 \%)$ \\
\hline College degree (2- or 4-year) & $885(38.7 \%)$ \\
\hline Graduate degree & $895(39.1 \%)$ \\
\hline \multicolumn{2}{|l|}{ Income, $n(\%)$} \\
\hline$<\$ 20,000$ & $797(35.2 \%)$ \\
\hline$\$ 20,000-60,000$ & $801(35.4 \%)$ \\
\hline$\$ 60,000-100,000$ & $369(16.3 \%)$ \\
\hline$\$ 100,000+$ & $296(13.1 \%)$ \\
\hline \multicolumn{2}{|l|}{ Mental health: mean, median (SD) } \\
\hline PHQ-9 timepoint 1 & $7.10,6(5.99)$ \\
\hline PHQ-9 timepoint 2 & $8.31,7(6.43)$ \\
\hline GAD-7 timepoint 1 & $5.78,4(5.21)$ \\
\hline GAD-7 timepoint 2 & $8.89,8(6.22)$ \\
\hline
\end{tabular}

${ }^{\text {a Individuals could select more than one option; thus, categories are not }}$ mutually exclusive

${ }^{b}$ This includes people who were assigned a sex of birth of male or female, and only gender is reported here; thus, gender minority people may be found in all categories

${ }^{c}$ Cisgender is listed here as an identity label. Cisgender people can be found in multiple categories and may not endorse this identity label

Acknowledgments: The PRIDE Study is a community-engaged research project that serves and is made possible by LGBTQ+ community involvement at multiple points in the research process, including the dissemination of findings. We acknowledge the courage and dedication of The PRIDE Study participants for sharing their stories; the careful attention of PRIDEnet Participant Advisory Committee (PAC) members for reviewing and improving every study application; and the enthusiastic engagement of PRIDEnet
Ambassadors and Community Partners for bringing thoughtful perspectives as well as promoting enrollment and disseminating findings. For more information, please visit https://pridestudy.org/ pridenet.

Annesa Flentje, $\mathrm{PhD}^{1,2,3}$

Juno Obedin-Maliver, $M D^{3,4}$

Micah E. Lubensky, $P h D^{1,3}$

Zubin Dastur, $\mathrm{MPH}^{3}$

Torsten Neilands, $\mathrm{PhD}^{5}$

Mitchell R. Lunn, $M D^{3,6}$

${ }^{1}$ Community Health Systems, University of California, San Francisco,

San Francisco, CA, USA

${ }^{2}$ Alliance Health Project, Department of Psychiatry, School of Medicine, University of California,

San Francisco, CA, USA

${ }^{3}$ The PRIDE Study/PRIDEnet, Stanford University School of Medicine,

Stanford, CA, USA

${ }^{4}$ Department of Obstetrics and Gynecology, Stanford University School of Medicine,

Stanford, CA, USA

${ }^{5}$ Center for AIDS Prevention Studies, Department of Medicine, School of Medicine, University of California,

San Francisco, CA, USA

${ }^{6}$ Division of Nephrology, Department of Medicine, Stanford University School of Medicine,

Stanford, CA, USA

Corresponding Author: Annesa Flentje, PhD; The PRIDE Study/ PRIDEnet, Stanford University School of Medicine, Stanford, CA, USA (e-mail: annesa.flentje@ucsf.edu).

Open Access This article is licensed under a Creative Commons Attribution 4.0 International License, which permits use, sharing, adaptation, distribution and reproduction in any medium or format, as long as you give appropriate credit to the original author(s) and the source, provide a link to the Creative Commons licence, and indicate if changes were made. The images or other third party material in this article are included in the article's Creative Commons licence, unless indicated otherwise in a credit line to the material. If material is not included in the article's Creative Commons licence and your intended use is not permitted by statutory regulation or exceeds the permitted use, you will need to obtain permission directly from the copyright holder. To view a copy of this licence, visit http://creativecommons. org/licenses/by/4.0/.

Funding Information A.F. was partially supported by the National Institute on Drug Abuse (grant number K23DA039800). J.O.M. was partially supported by the National Institute of Diabetes, Digestive, and Kidney Disorders (grant number K12DK111028). Research reported in this article was partially funded through a Patient-Centered Outcomes Research Institute (PCORI) Award (award number PPRN-1501-26848) to M.R.L. The statements in this article are solely the responsibility of the authors and do not necessarily represent the views of PCORI, its Board of Governors or Methodology Committee, nor of the National Institutes of Health. The funders had no role in study design, data collection and analysis, decision to publish, or preparation of the manuscript.

A.F. had full access to all the data in the study and takes responsibility for the integrity of the data and the accuracy of the data analysis. 


\section{REFERENCES}

1. The Lives and Livelihoods of Many in the LGBTQ Community Are at Risk amidst the COVID-19 Crisis. Human Rights Campaign Foundation; 2020. Available at: https://assets2.hrc.org/files/assets/resources/COVID19IssueBrief-032020-FINAL.pdf. Accessed April 21, 2020.

2. Lunn MR, Lubensky ME, Hunt C, et al. A digital health research platform for community engagement, recruitment, and retention of sexual and gender minority adults in a national longitudinal cohort study-The PRIDE Study. J Am Med Inform Assoc 2019;26(8-9):737-748.
3. Kroenke K, Spitzer RL. The PHQ-9: a new depression diagnostic and severity measure. Psychiatr Ann 2002;32(9):509-515.

4. Spitzer RL, Kroenke K, Williams JB, Löwe B. A brief measure for assessing generalized anxiety disorder: the GAD-7. Arch Intern Med 2006; 166(10): 1092-1097.

Publisher's Note: Springer Nature remains neutral with regard to jurisdictional claims in published maps and institutional affiliations. 